\title{
Thinking of Chemical Teaching Based on Project Teaching Method
}

\author{
Shunyi Yang, Chunhong Yuan, Gaohua Jiang \\ School of Metallurgy and Chemical Engineering, Kunming Vocational and Technical College of \\ Industry, Kunming Yunnan, 650302, China
}

Keywords: Chemical teaching, Project teaching, Traditional teaching method, Teaching design, Experiment

\begin{abstract}
The project-oriented teaching method stresses its full contents of theoretical knowledge, understanding learning, learning, learning methods Practical Action kneaded together, contributed to a new interactive learning environment "by doing from." Teaching in such a perfect fit into the project a focus on theory and practice of combining operations subjects chemistry, because chemistry teaching project teaching at stimulating the students' interest in studying chemistry, but also encourage them to pay more attention in the learning process and cooperation creativity, comprehensive quality greatly improved.
\end{abstract}

\section{Introduction}

As a complete teaching program, students learn to cooperate and participate in the task of progressive layers crack method in the project pedagogy, truly a "learning by doing", so the project is a teaching method to encourage everyone to participate therein creative practice, the results of which it is not the focus of the project is completed, but the project is completed the process and to improve student learning brought results.

\section{Project teaching method}

\section{Features of project teaching method}

\section{Students-centered}

In the project teaching, teachers should combine the characteristics of disciplines and students meet the learning needs of the characteristics of the design in accordance with the teaching content, thus achieving students' knowledge base and skills enhancement purposes. Project teaching general is organized in small groups to start teaching model, which encourages students to learn together, discuss together, practice together, and teachers in the course of the discussion, and students to discuss the project plans program to enable students to complete the entire project in the writing process. Of course, students can accord their own knowledge and skills, interests and ideas freely design the program, while teachers in this process, primarily as counseling and review party, not too much involved in the students' projects and programs to create and resolution process. Therefore we can say is people-oriented project teaching, which encourages students to free play, learning by doing, and subtle knowledge to enhance their learning, mastery of skills, but also in the assessment process of the project method simply not good or bad, only good or better. Overall, the project has changed the traditional teaching method pedagogy school students' passive acceptance of knowledge and skills to perform the traditional status of passive course task, but in the process of training projects seek to build knowledge and skills system, the real has become the absolute subject teaching activities.

\section{Emphasize quality education and training}

In today's higher education environment, simply no longer enough to master knowledge and skills, schools and teachers should also be more for students to acquire more specialized vocational skills for the future to seek a place in society and sake. Just as in chemistry teaching, teachers not only to teach students theoretical knowledge, but also should be through a combination of theory and practice ways for students to create a professional job situation with a certain degree of truth, as they simulate a virtual working environment. For example, many colleges and universities will be on the construction 
of the training center for students, creating a "school-enterprise cooperation," the opportunity for students to experience the hardships of the chemical industry work experience and charm in the course of practice. In the practical operation of the process, students explore the chemical knowledge, self-learning, the ability to analyze and solve problems will be strengthened so that the Project teaching is extremely good teaching methods in line with the current quality of education, its practical operation not only helps student growth, but also create more opportunities for social enterprise talent selection.

\section{Objective of project teaching}

Project teaching has two goals, the first point is to promote the education of students from 3R steering 3T, the so-called 3R refers to the traditional teaching students to take seriously for reading, arithmetic, writing. But in the contemporary information society, higher education greater emphasis on knowledge and skills students have learned the technology, transference and teaming, namely 3T.

Second, it is to train students in modern "five qualities." The so-called five qualities, refers to the sensitivity found the problem is finding the time, work time flexibility thinking, independence to solve problems, and fluency problems, and express check for problems when rigor. Five of these projects reflects the teaching method is to require students to be able to quickly and accurately recognize the problem and be able to find a reasonable solution to the problem, and more emphasis on addressing the issue of diversity. In this thinking, problem-solving system, students will be able to strengthen the capacity of the dialectic; demonstrated vision of the problem will become more open. It is clever to win, rather than to go straight to [1].

\section{Chemistry teaching design based on project teaching}

\section{Analysis of basic considerations of project teaching design}

Teaching is designed primarily for project design basis and should be based on the implementation of the practical requirements to start teaching, this article will detail.

Project teaching design consideration based on daily life

In chemistry teaching, it is essential to select projects in the emphasis on quality education today, but also close to the life of the project pedagogy, mining themes from life, and expand research, which is a "student-centered" basic teaching strategy in principle. For example, in chemistry education can be, for example, "about the rain $\mathrm{PH}$ value measurement," this project workable and very close to the student life, and allow students something to look forward, like in life, there are many cases of chemical practical operation, if from life mining refining the students' interest, so chemistry education project based pedagogy will be easily expanded.

Project teaching design consideration based on teaching materials

In the 21st century, our chemistry textbook higher education is already quite mature, in terms of both the theory and practice of refining, but what kind of teaching methods to play textbook educational content is the most important. Project teaching will be able to accurately grasp the direction of teaching materials and teaching, designed around teaching start teaching methods to achieve educational purposes. It does not just extract basic textbook knowledge, it did mobilize student interest in learning and problem-solving abilities. Teachers should be based on the content of textbooks involved to design different projects, but its principles must be done as close to life, such as food relates to the oxidation reaction that occurs when a long-term placement results in the formation of its deterioration corruption, acid rain and $\mathrm{PH}$ value testing and so on. Teachers can even lead students to participate in the process of operational practices among school, and student teaching project together, identify problems and develop their ability to solve problems. .

\section{Requirements for implementation of project teaching}

Project teaching is not only for students but also for teachers to expand; essentially it emphasizes the tacit understanding between the two sides of teaching and integrity. So these project-based teaching methods for teachers and students were requested.

\section{Requirements for teachers}

Unlike the traditional teaching model, Project teaching higher requirements for teachers, teachers not only need a simple lesson, but also for the course set up a whole train of thought, it examines the 
creative ability and classroom teaching teachers in curriculum design ability to improvise. Since it is a project, it shows that in the course of implementation is subject to change, teachers must not only be done on the students time to mobilize, control of student learning, emotional movements, but also to make a positive adjustment in accordance with the actual situation of students, in order to summarizes the characteristics of students and interest orientation, the course of the project perfect.

\section{Requirements for students}

The restraint that teaching methods bring to students include learning approach and learning attitude two ways. First, the project pedagogy must change the way students learn to play the role, to enable students to go deep to explore a wide range of projects promoted by teaching traditional passive acceptance of lazy learning ways and actively seek collaborative active learning approach, in this study transition mode, the students' curiosity and creativity will be excited to problem solving skills will be further strengthened. And as mentioned above, Project teaching requirements for students also focus on flexible combination of subject knowledge and life, which knowledge to the design of life whether students will learn is very important, and this is the future of professional competence for students Training in advance.

On aspect of learning attitude, teacher education programs in the grouping, and for each team member to establish a separate task, assign roles, students must play their role seriously and accomplish the task, so the project is a teaching method for students involved in the project an opportunity to experience the initiative, each individual project tasks must be completed in order to make their fair share of the overall task of the Panel to complete is completed. Therefore Project teaching is to require rigorous teaching and learning process, every student must take that step, with the practice of action to strengthen their self-confidence and ability, while improving team pride. At the same time, this is a upgrade of emotional communication between teachers and students.

\section{Implementation process of project teaching}

Theoretical teaching teach students "how to do", the practice of teaching to teach students "why do", project teaching comprehensive law is above two points, so the complete project implementation process should be as follows teaching.

\section{Determination of project task}

Presented by teachers of one or several project tasks envisaged, and the students brainstorm the final results and the actual situation based on the discussions to determine the project tasks and mission objectives.

Development of plan

Discussions around the identified projects to collect information develop a work plan for the project undertaken and identify the specific work steps. When the project is done, the feasibility of the program of activities by the classroom teacher and the formation of a complete, announced the project started.

\section{Implementation of plan}

Students are grouped division of tasks, a clear allocation of responsibilities for each group and activities expanded form, based on the activities planned to expand the project.

Evaluation and check

In project activities to a certain progress, the teacher will ask students to work activities carried out in this group of self-examination and the results of self-evaluation, peer review and then expand the groups, and finally unified inspection and evaluation by teachers. If found no problems during the inspection, teachers and students will be made to explore solutions. Through inspection and evaluation, project results obtained are analyzed reasons for the differences, while the degree of completion of the project is further enhanced.

Filing

After the project is completed, the project classifies archived and saved for teaching record. Some outstanding projects with practical value can also serve as a future reference for student teaching project put forward in order to improve the progress of the Project Approach [2]. 


\section{Chemistry teaching case analysis based on project teaching}

In chemistry teaching, Project teaching has been widely used, it caters to the chemical teaching that emphasizes practical, cooperative and life needs. This paper presents a simple case of project-based chemistry teaching pedagogy, and extending out of the two sub-projects to demonstrate comprehensive Project teaching in chemistry teaching process.

\section{Project teaching preparation work based on the life of rainwater $\mathrm{PH}$ value measurement}

Before teaching activities begin, first as student groups, in order to ensure the quality and fairness of the project teaching in the form of heterogeneous grouping, better academic performance and poorer students with strong organizational skills and organizational capacity of poor student points as a group, realize the strength of the match. Set the number of each group to ensure that 4-7 people, and set up a "project leader" position to ensure full implementation of group projects process. Projects "PH value measurement rain" for the subject project, students examine the changing nature of inorganic non-metallic compounds and elements and important Homologous learning. In addition, outside the main project is also divided into two sub-projects in order to develop students' knowledge of outward expansion capability.

\section{Major project: Measure of rain water $\mathrm{PH}$ value}

Expand the main purpose of the project is to strengthen the $\mathrm{PH}$ value measured on theory before the students have learned, and to develop them to explore their own deep content knowledge, practical ability to learn cooperative learning. First, let students access to relevant information on rain $\mathrm{PH}$ value, a correct understanding of the purpose and methods of measuring rain $\mathrm{PH}$ value. Then in project activities, teachers set up for the task group to explore the acid rain problem, discuss as a group after the unit show the research results, the final class assessment and project summary.

\section{Subproject extension}

\section{Study cause of acidic rain}

The subprojects is to study acid rain presented reasons, the purpose is to equip students with sulfuric correct test. Preview content can be arranged for students before class, so that they take the initiative to advance understanding of access to information component of acid rain encountered in life, to carry out project activities Teachers give students theoretical guidance before, then let the students in groups to expand component of acid rain in the classroom activity. Similarly, after the completion of project activities were all evaluated and summarized.

The reaction phenomenon of magenta solution and sulfur dioxide

Take students into the lab to do experiments, to verify the reaction solution and the carbon dioxide phenomenon between magenta and then observe the changes in heating. Expand the sub-project is aimed to equip students with the principles of sulfur dioxide bleaching, and students learn to observe, analyze problems. Through experiments, students learn the practical role in acid rain, sulfur dioxide, and further defined the acid rain on people, the environment harm.

In addition, teachers can also be extended to acid rain $\mathrm{PH}$ value measurement project based on the formation of acid rain in a variety of ways, such as nitrogen is converted to nitric acid process, the nature of ammonia, etc., to achieve the purpose of giving top priority to this issue from acid rain, verification project Teaching effectiveness and comprehensiveness [3].

\section{Summary}

This paper analyzes the project teaching guidelines and practices in the teaching of chemistry, it proved constructive Human characteristics and personality development of its students. Emphasizing quality education today, our education is in need of such a combination of theory and practice emphasizes more flexible thinking and flexible teaching methods. But also understand that in the current situation, project teaching school in full swing both in the hardware is there is a certain degree of difficulty on the software, so this reform and practice also requires a long process and the courage, at the same time continue to forge ideas to seek a breakthrough, step by step to broaden their horizons, to create ideas, form the actual teaching behavior. 


\section{Acknowledgments}

This article is a project of Yunnan Province Department of Education Fund for Scientific Research, Project No: 2014Y554.

\section{References}

[1] Wang Meiqin. Study on the application of project teaching in vocational hygienic middle school chemical teaching. Shandong Normal University, 2008.14-17.

[2] Wang Jianfeng. Study pf project teaching in vocational chemical engineering courses. Shanghai Normal University, 2012.15-18.

[3] Gao Jiren. Application of project teaching in higher vocational medical chemical teaching. Chemical education, 2015,36(2):52-56. 